\begin{tabular}{|c|c|c|}
\hline \multirow[b]{4}{*}{ 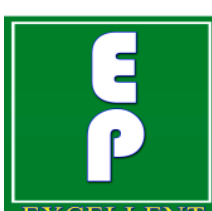 } & Int.J.Curr.Microbiol.App.Sci (2016) 5(3): $42-46$ & \multirow{4}{*}{ 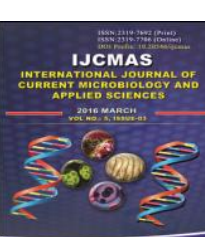 } \\
\hline & \multirow{4}{*}{$\begin{array}{l}\text { International Journal of Current Microbiology and Applied Sciences } \\
\text { ISSN: 2319-7706 Volume } 5 \text { Number 3(2016) pp. 42-46 } \\
\text { Journal homepage: http://www.ijcmas.com }\end{array}$} & \\
\hline & & \\
\hline & & \\
\hline PUBLISHERS & & \\
\hline
\end{tabular}

Original Research Article

http://dx.doi.org/10.20546/ijcmas.2016.503.006

\title{
A Comparative Study of Menstrual Practices among Urban and Rural Adolescent School Girls in Bareilly District, India
}

\author{
Priyanka Kumar*, S.B. Gupta, Imtiaz Danish and Agrawal Nipun \\ Department of Community Medicine, Shri Ram Murti Smarak Institute of \\ Medical Sciences, Bareilly (UP), India \\ *Corresponding author
}

\begin{abstract}
A B S T R A C T
Keywords

Menstrual

hygiene,

Menstruation,

Comparative

study, Rural,

Urban,

Adolescent.

Article Info

Adolescence in girls has been recognized as a special period which signifies the transition from girlhood to womanhood. Globally, adolescent girls constitute about $1 / 5$ th of total female population. More than just a physiological process, menstruation may be looked on as a restriction on women's religious and social traditions or as a taboo. To compare the practices of urban and rural school going adolescent girls regarding menstrual hygiene. It was a descriptive cross sectional study carried out in Government and private schools located in the areas served by UHTC and RHTC of Department of Community Medicine, SRMS IMS, Bareilly (UP). The study was conducted over a period of one year. Adolescent girls studying in $6^{\text {th }}$ to $10^{\text {th }}$ class in selected schools comprised the study population. Inclusion criteria were adolescent girls aged 10-19 years who had attained menarche and were studying in 6th to 10th class in the selected schools. Threefourth $142(75.5 \%)$ of rural girls were following restrictions during menses as compared to less number of urban subjects 126 (71.6\%). The most common restriction followed was not attending religious function as practiced by $73.9 \%$ and

Accepted:

07 February 2016

Available Online:

10, March 2016 $66.7 \%$ of rural and urban girls respectively. Study on the use of material during menses revealed that the use of sanitary pads was more common among urban adolescent girls $(62.5 \%)$ compared to rural $(35.1 \%)$. Most common reason cited for not using sanitary pad was high cost as reported by $42.6 \%$ and $43.9 \%$ of rural and urban girls respectively. Overall menstrual practices were better in urban as compared to rural girls.
\end{abstract}

\section{Introduction}

Adolescence in girls has been recognized as a special period which signifies the transition from girlhood to womanhood. Globally, adolescent girls constitute about $1 / 5$ th of total female population (Jogdand and Yerpude, 2011). While in India, adolescent girls account for a little more than one-fifth of the population (21.4\%).
Menarche is the most important event in the life of an adolescent girl. During puberty, hormonal, psychological, cognitive and physical changes occur simultaneously and interactively making physiological development a challenge adolescents have to face, with emotional, social and behavioural dimensions. More than just a physiological 
process, menstruation may be looked upon as something badly religion and social traditions or as a taboo (Dube and Sharma, 2012).

For most girls, menarche is a negative, frightening experience, or, at the best, a nuisance, or is something to fear or to be ashamed of. Restrictions in daily activities such as not being allowed to take bath, change clothes, comb hair, entering holy places and even dietary restrictions are also imposed during the menstrual (Dube and Sharma, 2012).

The objectives of this study are to compare menstrual practices in rural and urban adolescent school girls in district, Bareilly.

\section{Materials and Methods}

It was a descriptive cross sectional study carried out in Government and private schools located in the areas served by Urban Health Training Centre (UHTC) and Rural Health Training Centre (RHTC) of Department of Community Medicine, SRMS IMS, Bareilly (UP). The study was conducted over a period of one year i.e. $1^{\text {st }}$ May 2014 to $30^{\text {th }}$ April 2015. Inclusion criteria were adolescent girls aged 10-19 years who had attained menarche and were studying in $6^{\text {th }}$ to $10^{\text {th }}$ class in the selected schools.

A sample size of 210 was calculated based on the prevalence of awareness of menstruation prior to attainment of menarche among school going adolescent girls which was found to be $67 \%$ in a study conducted by Dasgupta and Sarkar (2008) and taking a relative allowable error of $10 \%$ considering another $10 \%$ non-response rate.

Multistage random sampling was applied to select schools and also 21 girls each from classes $6^{\text {th }}$ to $10^{\text {th }}$ from selected schools.
Visits were made to the schools for conducting face-to-face interviews using pre-designed, pre-tested semi-structured questionnaire. In the end, after the interview, the girls were given health education and counselled in areas where their knowledge was lacking and needed reinforcement.

Data were entered using Microsoft Excel 2010 and statistical analysis was done using IBM SPSS v 20.0.0. Categorical variables were analyzed using proportions and percentages. Association between categorical variables was established by Chi square test. $\mathrm{Z}$ test was used for testing of proportion. Continuous variables were summarized by mean and standard deviation (SD).

\section{Results and Discussion}

Table 1 showed that out of 420 adolescent girls who participated in the study, 364 $(86.7 \%)$ had attained menarche similar to the findings of Dasgupta and Sarkar (2008) and Thakre et al. (2011).

Table 2 showed that reaction to first menses, that out of 364 adolescent girls who had attained menarche, principle emotion associated with first menses was scared $187(51.4 \%)$ as revealed by more than half of rural subjects $103(54.8 \%)$ and $84(47.7 \%$ ) of urban subjects. There was not any reaction from $24(12.7 \%)$ and $29(16.5 \%)$ of rural and urban participants respectively. The findings is comparable to study by Kamath et al. (2013) study in which rural participants 148 $(52.9 \%)$ were found to be more scared than urban participants 125 (46.3\%). In the same study there wasn't any reaction to first menses as observed from $16.8 \%$ and $26.3 \%$ of the rural and urban adolescent girls respectively.

Table 3 showed the types of restrictions imposed on adolescent girl during menses. 
Among the 268 girls practicing any type of restrictions, most common being $(70.5 \%)$ attending any religious functions and least being $(7.8 \%)$ not allowed to attend their schools during menstruation. $101(37.7 \%)$ were not allowed to cook, $74(27.6 \%)$ were not allowed to do household work, 96 $(35.8 \%)$ were not allowed to play and 61 $(22.7 \%)$ were made to sleep separately during menstruation. Only $61(22.7 \%)$ of the subjects did not practice any restrictions.

Table.1 Distribution of Adolescent Girls According to Menarche

\begin{tabular}{|c|r|r|r|r|r|}
\hline \multirow{2}{*}{$\begin{array}{c}\text { Attained } \\
\text { Menarche }\end{array}$} & Rural $(\mathrm{n}=210)$ & Urban $(\mathrm{n}=210)$ & Total $(\mathrm{n}=420)$ & \multirow{2}{*}{ Z test } & \multirow{2}{*}{ P Value } \\
\cline { 2 - 4 } & Frequency $(\%)$ & Frequency $(\%)$ & Frequency $(\%)$ & & \multirow{2}{*}{2.97} \\
\hline Yes & $188(89.5)$ & $176(83.8)$ & $364(86.7)$ & \multirow{2}{*}{0.08} & \\
\hline No & $22(10.5)$ & $34(16.2)$ & $56(13.3)$ & \\
\hline
\end{tabular}

Table.2 Distribution of Study Subjects According to their Reaction to First Menses

\begin{tabular}{|l|r|r|r|r|r|}
\hline & Rural $(\mathrm{n}=188)$ & Urban $(\mathrm{n}=176)$ & \multicolumn{1}{|c|}{ Total $(\mathrm{n}=364)$} & \multirow{2}{*}{ P value } & \multirow{2}{*}{$\mathrm{Z}$ test } \\
\cline { 2 - 4 } & Frequency(\%) & Frequency(\%) & Frequency(\%) & & \\
\hline Happy & $15(7.0)$ & $17(9.6)$ & $32(8.8)$ & 0.71 & 0.36 \\
\hline Scared & $103(54.8)$ & $84(47.7)$ & $187(51.4)$ & 0.62 & 1.86 \\
\hline Shocked & $24(12.7)$ & $35(19.9)$ & $59(16.2)$ & 0.122 & 1.54 \\
\hline Sin & $6(3.2)$ & $2(1.1)$ & $8(2.2)$ & 0.153 & 1.42 \\
\hline Confused & $16(8.5)$ & $9(5.1)$ & $25(6.8)$ & 0.14 & 1.44 \\
\hline No reaction & $24(12.7)$ & $29(16.5)$ & $53(14.5)$ & 0.46 & 0.73 \\
\hline
\end{tabular}

Table.3 Distribution of Study Subjects According to Types of Restrictions Followed During Menses

\begin{tabular}{|c|c|c|c|c|c|}
\hline & Rural (n=142) & Urban $(n=126)$ & Total $(n=268)$ & \multirow{2}{*}{ P-value } & \multirow{2}{*}{$\mathrm{Z}$ test } \\
\hline & Frequency $(\%)$ & Frequency $(\%)$ & Frequency $(\%)$ & & \\
\hline $\begin{array}{l}\text { Don't attend religious } \\
\text { function }\end{array}$ & $105(73.9)$ & $84(66.7)$ & $189(70.5)$ & 0.039 & 2.059 \\
\hline Don't cook & $60(42.2)$ & $41(32.5)$ & $101(37.7)$ & 0.03 & 2.16 \\
\hline $\begin{array}{l}\text { Don't do household } \\
\text { work }\end{array}$ & $42(29.6)$ & $32(25.4)$ & $74(27.6)$ & 0.20 & 1.28 \\
\hline Don't play & $59(41.5)$ & $37(29.4)$ & $96(35.8)$ & 0.010 & 2.55 \\
\hline Sleep separately & $42(29.6)$ & $19(15.0)$ & $61(22.7)$ & 0.0014 & 3.18 \\
\hline
\end{tabular}

Table.4 Distribution of Study Subjects According to the Material used During Menses

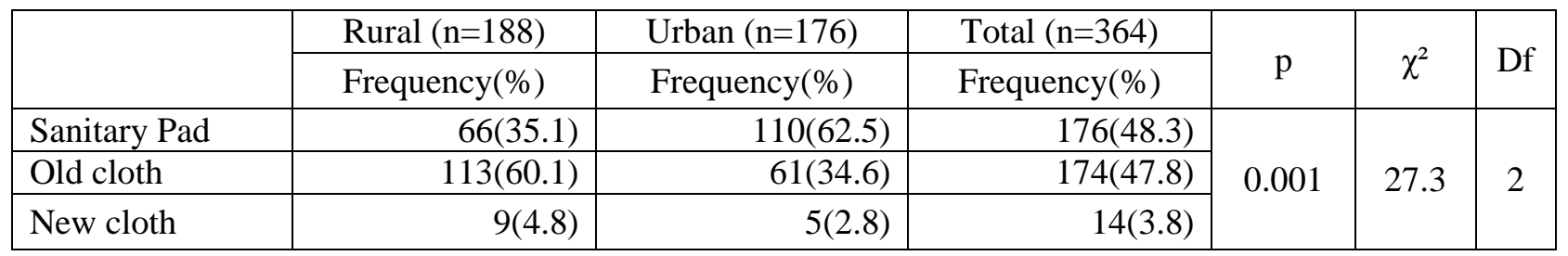


Table.5 Distribution of Study Subjects According to the Frequency of Changing of Pads

\begin{tabular}{|l|r|r|r|r|r|}
\hline & Rural $(\mathrm{n}=66)$ & Urban $(\mathrm{n}=110)$ & \multicolumn{1}{|c|}{ Total $(\mathrm{n}=176)$} & \multirow{2}{*}{ P value } & \multirow{2}{*}{$\mathrm{Z}$ value } \\
\cline { 2 - 4 } & Frequency(\%) & Frequency $(\%)$ & Frequency(\%) & & \\
\hline Once & $6(9.0)$ & $7(6.3)$ & $13(7.4)$ & 0.77 & 0.28 \\
\hline Twice & $35(53.0)$ & $64(58.2)$ & $99(56.2)$ & 0.008 & 3.33 \\
\hline Thrice & $25(37.8)$ & $39(43.6)$ & $64(36.3)$ & 0.57 & 1.9 \\
\hline
\end{tabular}

Table.6 Distribution of Study Subjects According to School Absenteeism and the Reasons for not Attending School During Menses

\begin{tabular}{|c|c|c|c|c|c|}
\hline & Rural $(\mathrm{n}=188)$ & $\begin{array}{l}\text { Urban } \\
(\mathrm{n}=176)\end{array}$ & $\begin{array}{c}\text { Total } \\
(\mathrm{n}=364)\end{array}$ & \multirow{2}{*}{$\begin{array}{c}\mathrm{P} \\
\text { value }\end{array}$} & \multirow{2}{*}{$\begin{array}{c}\mathrm{Z} \\
\text { test }\end{array}$} \\
\hline & Frequency $(\%)$ & Frequency $(\%)$ & Frequency $(\%)$ & & \\
\hline \multicolumn{6}{|c|}{ Absent from school during menses } \\
\hline Yes & $84(44.7)$ & $72(40.9)$ & $156(42.8)$ & \multirow{2}{*}{0.490} & \multirow{2}{*}{0.475} \\
\hline No & $104(55.3)$ & $104(59.1)$ & $208(57.2)$ & & \\
\hline \multicolumn{6}{|c|}{ Reason for absent from school during menses $(n=156)$} \\
\hline Lack of privacy & $19(22.6)$ & $10(13.8)$ & $29(18.6)$ & 0.10 & 1.63 \\
\hline $\begin{array}{l}\text { Lack of provision for disposal } \\
\text { of soiled pads/cloth }\end{array}$ & $22(26.2)$ & $18(25.0)$ & $40(25.6)$ & 0.64 & 0.46 \\
\hline $\begin{array}{lll}\text { Lack of water supply for } \\
\text { cleaning }\end{array}$ & $7(8.4)$ & $4(5.6)$ & $11(7.0)$ & 0.27 & 1.08 \\
\hline Pain or discomfort & $9(10.7)$ & $15(20.8)$ & $24(15.4)$ & 0.12 & 1.5 \\
\hline Fear of getting stain on clothes & $27(32.1)$ & $30(34.7)$ & $57(36.5)$ & 0.88 & 0.14 \\
\hline
\end{tabular}

These findings are contrary to the findings of Sapdoka et al. (2013) where $80.3 \%$ girls did not practice any restrictions during menstruation while $19.7 \%$ of the respondents practiced some restriction. Among those who practiced any restrictions, majority $(58.4 \%)$ weren't allowed to cook and visit temples followed by $25.0 \%$ girls who were not allowed to do the household work i.e. cooking and touching male family member.

Table.4 shows use of material during menses, revealing that almost half of the adolescent girls 176(48.3\%) were found to use sanitary pads during menstruation, 174 $(47.8 \%)$ girls used old cloth pieces and $14(3.8 \%)$ used new pieces of cloth. In rural girls, the use of sanitary pads was $66(35.1 \%)$ and in urban girls, it was $110(62.5 \%)$. The use of old clothes was $113(60.1 \%)$ in the rural girls and 61(34.6\%) in the urban girls and this difference was also found to be statistically significant $(\mathrm{p}=0.001)$.

These findings were contrary to Kamaljit et al. (2012) who reported that nearly one third $(31.0 \%)$ of the respondents was ignorant about the use of sanitary pad during menstruation. $69.0 \%$ of the respondents was using sanitary pads during menstruation whereas clean cloth was being used by 63 $(23.0 \%)$ while $(10.0 \%)$ were practicing any cloth or rag or cotton. In the present study, reasons for not using sanitary pads included high cost and lack of knowledge in both rural $52(42.6 \%)$ and urban areas 29(43.9\%).

Table 5 shows that more than half of rural $35(53.0 \%)$ and urban subjects $64(58.2 \%)$ were found to change their pads twice in a day meaning normal blood loss followed by 
$25(37.8 \%)$ and $39(43.6 \%)$ who changed their pads thrice indicating heavy blood loss.

The findings of present study are comparable to Sapdoka et al. (2013) study where almost half of the girls $(50.8 \%, 31)$ changed their pads two times a day meaning they have normal blood loss, in contrast to this, $40.9 \%$ (25) changed their pads more than three times a day indicating heavy blood loss.

Table 6 shows that $156(42.8 \%)$ of the adolescent girls were found to be absent from school during their menses. Out of 156 girls, most common reason given for being absent from school due to menstruation was fear of getting stain on clothes as reported by $57(36.5 \%)$ subjects followed by 40 (25.6\%) subjects who cited lack of availability for disposal of soiled pads or cloth. This trend was similar among both rural and urban adolescent girls. Abajobiri and Seme (2013) in his study found that the most common reason given for being absent during menstruation was fear of leakage or staining followed by Had non availability of pad to manage period.

In conclusion, overall, menstrual practices are better in the urban area as compared to rural area. Still, there is need for sensitizing the adolescent girls and increasing their knowledge towards hygienic menstrual practices.

\section{Acknowledgment}

Authors are thankful to the Chairman, Shri
Dev Murti, for making suitable arrangements for the research work. Special thanks to the women for their constant support.

\section{References}

Abajobiri, A.A., Seme, A. 2013 June. Reproductive health knowledge and services utilization among rural adolescents in Machakal district, Northwest Ethiopia. Asian J. Pharm. Nursing Med. Sci., 1(1) 2321-3639.

Dasgupta, A., Sarkar, M. 2008; April. Menstrual hygiene: how hygienic is the adolescent girl. Ind. J. Commun. Med., 33(2).

Dube, S., Sharma, K. 2012. Knowledge, attitude and practice regarding reproductive health among urban and rural girls: A comparative study. Ethno. Med., 6(2): 85-94.

Jogdand, K., Yerpude, P.A. 2011 Jul - Sep. Community based study on menstrual hygiene among adolescent girls. Ind. J. Mat. Ch. Health, 13(3): 2-6.

Kamaljit, K., Arora, B., Singh, G.K., Neki, N.S. April-June 2012. Social beliefs and practices associated with menstrual hygiene among adolescent girls of Amritsar, Punjab, India. JIMSA, 25(2): 69-70.

Kamath, R., Ghosh, D., Lena, A., Chandrasekaran, V. 2013. A study on knowledge and practices regarding menstrual hygiene among rural and urban adolescent girls in Udupi Taluk, Manipal, India. Gjmedph, (2)4.

Sabdoka, D., Sharma, D., Budhathoki, S.S., Khanal, V.K., Pokharel. H.P. 2013 Jul-Sept. Knowledge and practices regarding menstruation among school going adolescents. J. Kath. Med. Coll., 2(5): 12228.

Thakre, S.B., Thakre, S.S., Reddy, M., Rathi, N., Pathak, K., Ughade, S. 2011 Oct. Menstrual hygiene: knowledge and practice among adolescent school girls of saoner, Nagpur district. J. Clin. Diag. Res., 5(5): 1027-33.

\section{How to cite this article:}

Priyanka Kumar, Gupta, S.B., Imtiaz Danish and Agrawal Nipun. 2016. A Comparative Study of Menstrual Practices among Urban and Rural Adolescent School Girls in Bareilly District, India. Int.J.Curr.Microbiol.App.Sci. 5(3): 42-46. doi: http://dx.doi.org/10.20546/ijcmas.2016.503.006 